\title{
Everything is always (the liquid protocol)
}

\section{lizvlx}

UBERMORGEN, Austria

\section{Hans Bernhard}

UBERMORGEN, Austria

Construction, Deconstruction and Reconstruction of Money, visualised on an Apple ii Main Logic Board Schematic serving as vertical, trickle-down Timeline

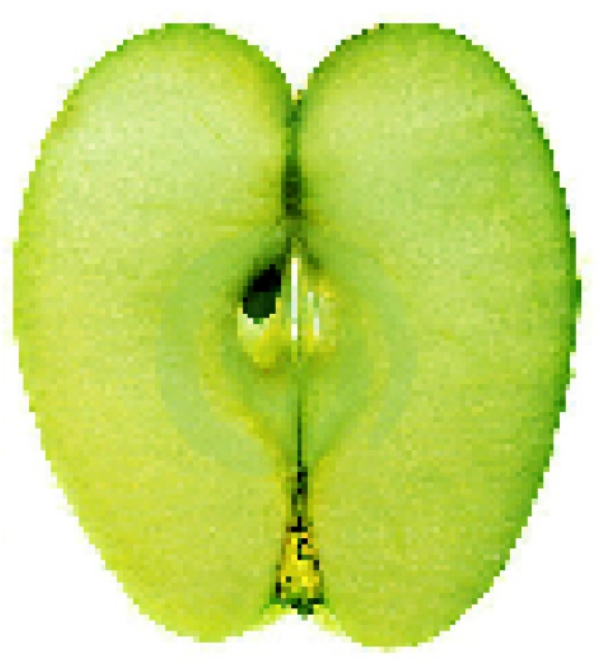

Figure 1. UBERMORGEN, APPLEii (vertical), 2013. Courtesy of the artist; Carroll/Fletcher, London; and GYRE, Tokyo (Money after Money).

\section{Do you believe that this apple is an apple?}

If fear rules, money disappears - or gathers at the completely wrong places. Money is the most boring and at the same time the most evil thing on earth. Obviously $99.9 \%$ of earth's population are not interested in money at all, versus $0.1 \%$ that are interested in money exclusively. Money brutalises. Money is coupled to the human psyche. Everybody fears losing 
money and because of this actual money is destroyed. If money is accepted as money, it simply means: it is about trust. Trust is not only cheaper - it is the only way money can come into existence. Money is a social construct. It can not be rescued via private individual actions - only collectively.

\section{Construction of the past}

Money is common, banal and old, yet still it has remained mysterious. There is no precise and definite definition of how money should be perceived and interpreted. Instead of this, volumes of money from MO to M3 are created, and each Central Reserve Bank defines them individually. There is no global agreement about what can be counted as money. With money international standards and norms - common for every photocopier or car - fail. So the unique, defined and agreed upon forbidden fruit is long gone; it was invented and has now disappeared. The apple is the primary symbol, the ultimate unit. The thing you can use and is healthy. Forbidden fruit is a phrase that originates from Genesis concerning Adam and Eve. In the narrative, the fruit came from the Tree of the Knowledge of Good and Evil and was eaten by Adam and Eve in the Garden of Eden. As a metaphor, the phrase typically refers to any indulgence or pleasure that is considered illegal or immoral. In Western Europe, the fruit was often depicted as an apple, possibly because of a misunderstanding of, or a pun on mălum, a native Latin noun which means evil (from the adjective malus), and mālum, another Latin noun, borrowed from the Greek $\mu n \lambda o v$, which means apple. In the vulgate, Genesis 2:17 describes the tree as de ligno autem scientiae boni et mali: "but of the tree (lit. wood) of knowledge of good and evil" (mali here is the genitive of malum). The larynx in the human throat, noticeably more prominent in males, was consequently called an Adam's apple, from a notion that it was caused by the forbidden fruit sticking in Adam's throat as he swallowed. Another theory as to why the Apple was chosen as the 'Forbidden Fruit' is the fact that when you cut an apple in half sideways (horizontally across its middle), then look at the centre of each half - the 'seeded' section - you will see the unmistakable image of a Pentagram. Some individuals have postulated that the Apple was selected by the early Roman Catholic Church as being the 'Forbidden Fruit' due to the image of a Pentagram found at its centre.

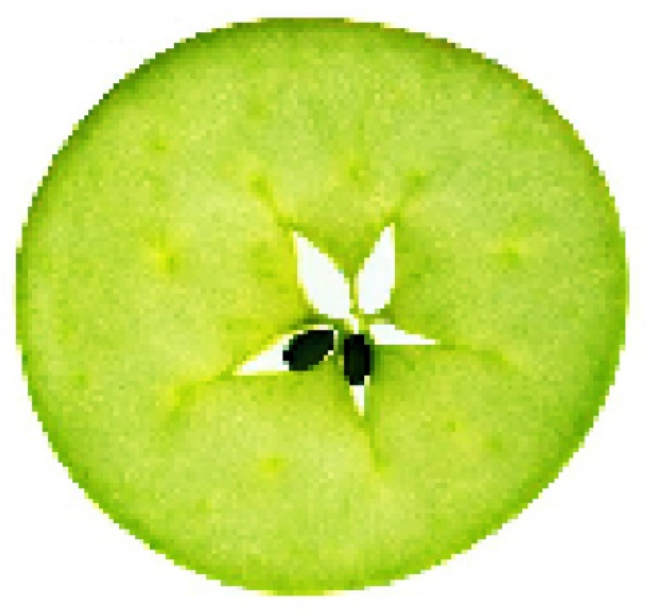

Figure 2. UBERMORGEN, APPLEii (horizontal), 2013. Courtesy of the artist; Carroll/Fletcher, London; and GYRE, Tokyo (Money after Money). 


\section{Deconstruction of the present}

It is part of the social mystery that there is no neutral product such as an apple. An apple is an apple and stays an apple; in contrast to money, where often it is hard to recognise whether it still exists or whether it has already disappeared. In the words of the Banker: 'liquidity' and 'solvency' are not always easy to distinguish. Even healthy states or companies can go bankrupt if investors believe in a crash or deny loans. The vernacular calls this phenomenon: 'One can talk himself into a crisis'. A physical illogicality: The one who has money gets more money, the one who has not gets none. There is no trickle-down effect, there is nothing coming through, in the opposite. It is a trickle-up effect. They suck the money up. Non-even distribution. In physics, everything has to be balanced; in monetary physics it is the opposite. Is there an opposite force to money? Money is expansive (power, freedom) but there is no counterpart balancing this extreme, perverted form of distribution. There is no normative theory. No experimental economic science. Just biased theory and the dictate of practice. Hence the deconstruction of trust and destruction of ideas by innovations such as contemporary derivatives: Structured Debt Obligations, Forwards, Futures, Options, Binary Options, Warrants, Swaps, Currency Futures, Bond Future, Gold Option, Turbo Warrant, Credit Default Option, Currency Forward, Currency Swap, Weather Derivative, Eurodollar Future, Interest Rate Swap, Equity Swap, WTI Crude Oil Futures. And by current markets: Exchange, Securities, Bond valuation, Corporate bond, Fixed income, Government bond, High-yield debt, Municipal bond, Common stock, Preferred stock, Registered share, Stock, Stock certificate, Stock exchange, Voting share, Credit derivative. Futures exchange, Hybrid security, Securitisation, Over-the-counter, Forwards, Options, Spot market, Swaps, Currency, Exchange rate, Commodity market, Money market, Reinsurance market, Real estate market, Practical trading, Clearing house, Financial market participants, Financial regulation, Finance series, Banks and banking, Corporate finance, Personal finance, Public finance.

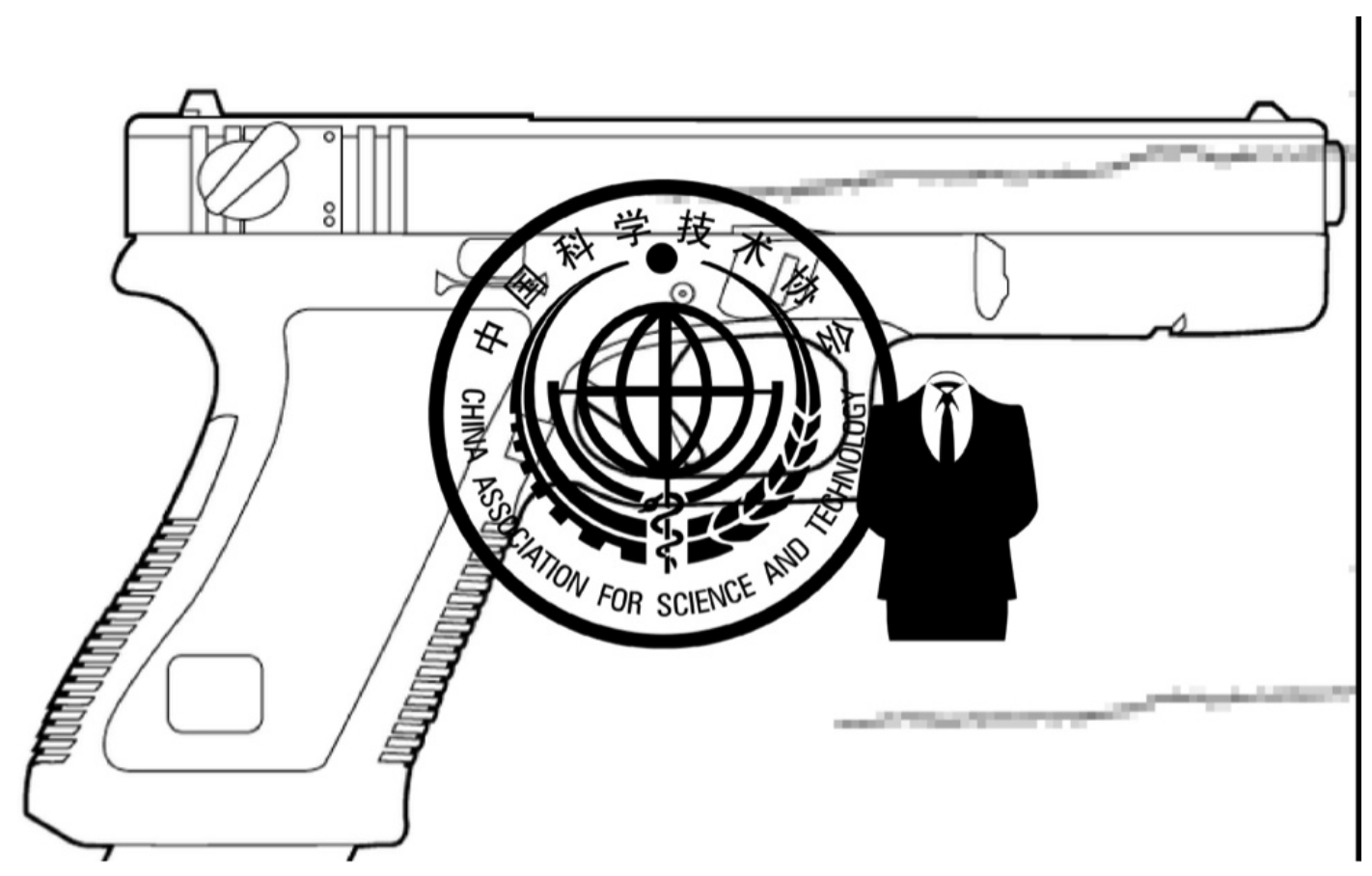

Figure 3. UBERMORGEN, APPLEii_Diagram (Detail), 2013. Courtesy of the artist; Carroll/Fletcher, London; and GYRE, Tokyo (Money after Money). 


\section{Reconstruction in the future}

Everything is. Every commodity, each thing, each social interaction, each water molecule, each forbidden fruit, each affirmation, each pixel. Everything is. Everything has been. Everything will be. There is no exchange. Always. There is no value. Always. There is no saving or conservation. Always. Everything is our potential. Everything is free. Always. Protocols are. Always. $1 / 5400$ of an apple is. Always. Everything vibrates. Always. Every pixel counts. Always. Everyone consensually hallucinates about Everything. Always. Everything is constantly renegotiating relations with everything else. There is no value storage, no means of measuring, no form of payment, no external rules, no formal requirements, just high-speed exchange of abstract needs and objects: post-human value detached from human needs. The new protocol serves as a common means for unrelated objects to communicate with each other. Transactions are randomised, bubbled and looped: Everything. Always. Everything, every aspect of human life is broken down into individually addressed atomic packages that are routed to ad hoc platforms in search of equivalents: 1/9000th of an orgasm is negotiated for $1 / 1000000$ th of a gram of cocaine or 1/5400th of an apple, 1/400th of a toothbrush is valued at $1 / 500000000$ of a second of EC2 cloud processing power or $1 / 100$ th of a potato or 1/99th of a breath of air. A high-level outburst of fury is valued at 1/150th of 1 second of ultimate and fundamental fear and this is again valued against $1 / 780$ th gram of coffee or $1 / 11110000$ th of a coal-mining machine and all of that combined is worth 1/99th of a Bitcoin. Things, feelings and services are exchanged and put in relation to each other. All these transactions are randomised and they are recurring and in loops and they exist in parallel. Live-feeds from data-centres hosting major search-engines, porn-sites, e-commerce platforms and financial services are combined with raw data from skype-therapy and health insurances, network statistics (speed, usage, users, routing), social security databases, credit card live transactions, statistical data of all sorts, live energy and logistics information, military data and uncountable other crucial or irrelevant data streams from platforms and entities that feed into the above described evolving ad hoc markets, generating exponential amounts of transactions. This data serves as impulse and direction-giver for the exchange of things, feelings and services. Bahamian zombie corporations are used as clearing-houses. They serve as proxies. The highest level of commercialisation imaginable is on the verge of happening and this situation demands a new liquid protocol, a new way to look at forms of payment, value storage and spending power. We reconstruct the current money system and take away the traditional means of money: payment tool, storage and measuring unit function. By doing so we create a protocol, a fluid high-speed network-dependable system that exists right in this very moment, and only then. Yes, a protocol is a common means for unrelated objects to communicate with each other, hence personal needs can be traded against coal-mining machines, water against sex and tech-services against food. Therefore establishing a temporary value for everything and establishing a post-human currency completely depending on network instances and electric power, transactions, storage, existence, meaning and dissolution, all within the cable or in radio-waves, alive while travelling and negotiating, vanished when stored. 


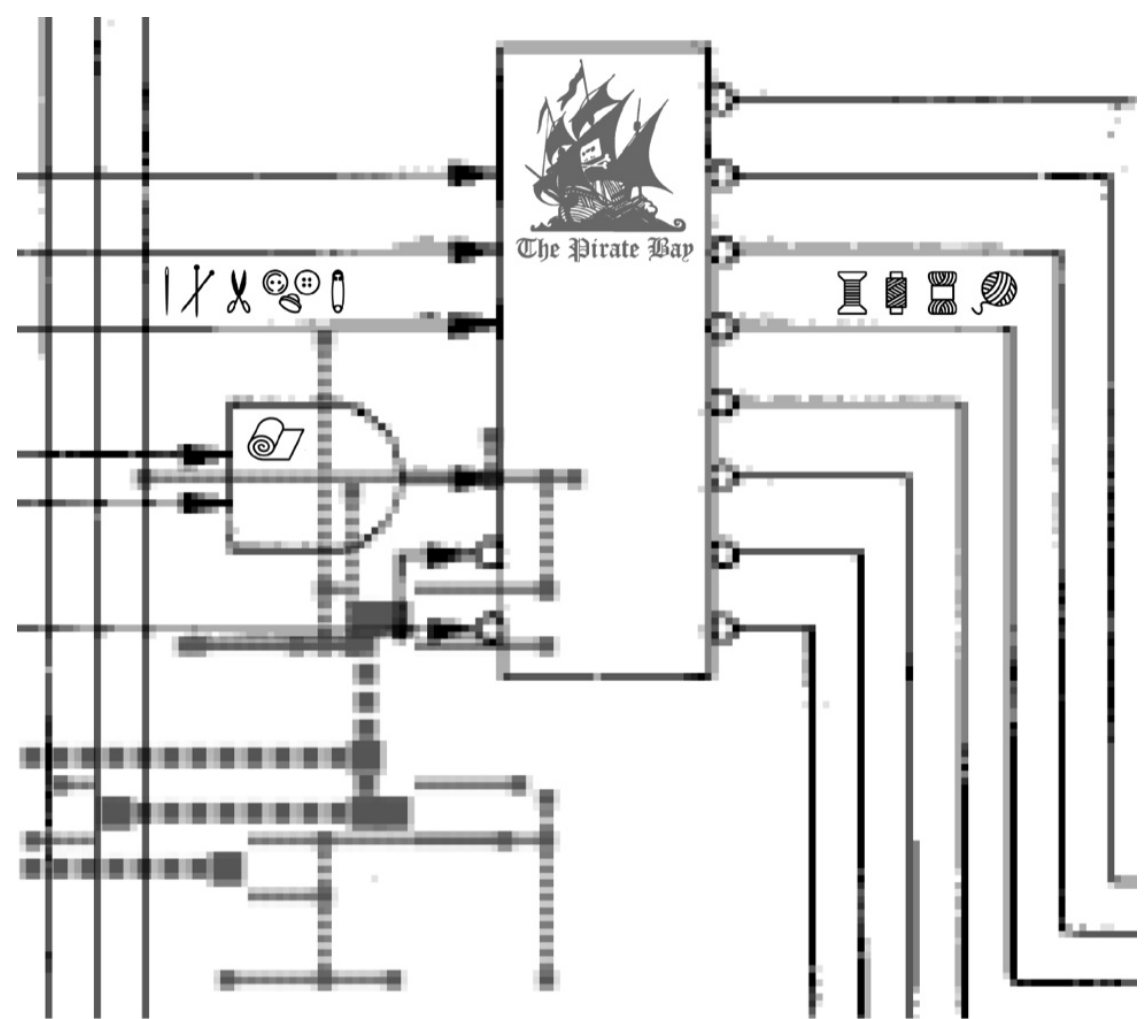

Figure 4. UBERMORGEN, APPLEii_Diagram (Detail), 2013. Courtesy of the artist; Carroll/Fletcher, London; and GYRE, Tokyo (Money after Money).

UBERMORGEN are lizvlx (AT, 1973) and Hans Bernhard (CH/USA, 1971), European artists and net.art pioneers. They tenaciously convert code \& language and concept \& aesthetics into digital objects, software art, net.art, installation, new painting, videos, press releases and actions. CNN described them as 'maverick Austrian business people' and the New York Times called Google Will Eat Itself 'simply brilliant'. Their main influences are Rammstein, Samantha Fox, Guns N' Roses \& Duran Duran, Olanzapine, LSD \& Kentucky Fried Chicken's Coconut Shrimps Deluxe. Visit their website at http://ubermorgen.com 